\title{
Digestibilidade do fósforo de alimentos de origem vegetal determinada em suínos em crescimento e terminação
}

\author{
Silvano Bünzen ${ }^{1}$, Horacio Santiago Rostagno², Darci Clementino Lopes², Flávio Augusto \\ Massakichi Hashimoto ${ }^{3}$, Paulo Cezar Gomes ${ }^{2}$, Lourdes Romão Apolônio ${ }^{3}$
}

\footnotetext{
1 Programa de Pós-graduação em Zootecnia - DZO/UFV.

2 Departamento de Zootecnia - UFV - 36571-000, Viçosa, MG.

${ }^{3}$ Doutor em Zootecnia - UFV - 36571-000, Viçosa, MG.
}

RESUMO - Objetivou-se determinar os coeficientes de digestibilidade aparente (CDAP) e verdadeira (CDVP) do fósforo de 11 alimentos de origem vegetal utilizados na alimentação de suínos. Foram utilizados 78 animais mestiços distribuídos em um delineamento experimental inteiramente casualizado, em arranjo fatorial $2 \times 2 \times 13$ (metodologia $\times$ fase $\times$ tratamento) e três repetições por tratamento (alimento-teste). Os coeficientes de digestibilidade foram avaliados utilizando-se, simultaneamente, duas metodologias (coleta total de fezes e uso de indicador fecal, $\mathrm{Cr}_{2} \mathrm{O}_{3}$ ) em duas fases de produção (crescimento e terminação), cada uma com 36 suínos com 25,0 \pm 3,0 e 60,0 \pm 5,0 kg de peso corporal, respectivamente. Determinaram-se os coeficientes de digestibilidade de 11 alimentos, uma ração-referência e uma ração com baixo conteúdo de fósforo total (0,03\%) para estimativa das perdas de fósforo endógeno nas duas fases de desenvolvimento. Os valores médios de CDAP e CDVP do fósforo encontrados com suínos em crescimento e terminação foram, respectivamente, 45,01 e 68,32\% para o milho; 31,3 e 66,97\% para o sorgo; 31,84 e 41,31\% para o farelo de glúten de milho (22\% PB); 38,28 e 53,20\% farelo de glúten de milho (60\% PB); 32,42 e 40,61\% para o farelo de algodão (30\% PB); 37,50 e 43,95\% para o farelo de algodão (40\% PB); 50,76 e 55,74\% para o farelo de trigo; 38,75 e 52,19\% para o farelo de soja; 33,61 e 41,21\% para o concentrado protéico de soja; 41,67 e 55,81\% a soja integral extrusada e, 56,84 e 66,56\% para a levedura desidratada de cana de açúcar. Não foram encontradas diferenças entre os CDAP e CDVP determinados pelas metodologias de coleta total de fezes e de indicador fecal. $\mathrm{Na}$ fase de terminação, os coeficientes de digestibilidade aparente e verdadeira dos alimentos testados foram maiores que os obtidos na fase de crescimento.

Palavras-chave: coleta total de fezes, fósforo digestível, óxido crômico

\section{Phosphorus digestibility from vegetal feed origins determined in growing and finishing pigs}

\begin{abstract}
The coefficients of apparent (CADP) and true (CTDP) digestibility of phosphorus of eleven plant feed of vegetal origins commonly used in swine feeds were determined in this research. Seventy eight crossbred barrows were distributed to completely randomized experimental design, with a factorial arrangement $2 \times 2 \times 13$ (methodology $\times$ phase $\times$ treatment) with three replicates per treatment. The digestibility coefficients were evaluated by using simultaneously both methodologies, total fecal collection and fecal marker $\left(\mathrm{Cr}_{2} \mathrm{O}_{3}\right)$, in two production periods, growing and finishing phases, using 36 pigs in each period, with average weight of $25 \pm 3$ and $60 \pm 5 \mathrm{~kg}$, respectively. The digestibility coefficients of 11 feeds, a reference diet and low phosphorus (0.03\%) diet were determined to estimate the phosphorus endogenous losses in the two phases. The average values of CADP and CTDP observed with pigs in the growing and finishing phases were: 45.01 and $68.32 \%$ for corn; 31.3 and $66.97 \%$ for sorghum; 31.84 and $41.31 \%$ for corn gluten feed (22\% CP); 38.28 and $53.20 \%$ for corn gluten meal (60\% CP); 32.42 and $40.61 \%$ for cottonseed meal (30\% CP); 37.50 and $43.95 \%$ for cottonseed meal (40\% CP); 50.76 and 55.74\% for wheat bran and middlings; 38.75 and 52.19\% for soybean meal; 33.61 and $41.21 \%$ for soybean protein concentrate; 41.67 and $55.81 \%$ for soybean full fat extruded; and 56.84 and $66.56 \%$ for yeast from alcohol distillery. There was not difference between the phosphorus digestibility coefficients obtained by the total fecal collection and the fecal marker methodologies. Pigs in the finishing phase showed higher CADP and CTDP of the feeds than those obtained with growing pigs.
\end{abstract}

Key Words: chromic oxide, digestible phosphorus, total fecal collection 


\section{Introdução}

O fósforo é um mineral essencial na formação da estrutura óssea e participa de inúmeros processos metabólicos, como a formação de membranas celulares e a utilização e transferência de energia (ATP). Esse mineral tem sido estudado não somente por sua importância econômica, uma vez que é o terceiro nutriente mais oneroso da ração para animais não-ruminantes, mas também por sua importância ambiental.

Do total de fósforo encontrado em grãos e subprodutos de origem vegetal, 60-80\% encontram-se na forma orgânica; o ácido fítico é o fosfoglicídeo mais abundante e, geralmente, forma sais com cátions (Ca, Mg, Zn, Fe), aminoácidos e amido (Sauer \& Ozimek, 1986). O fósforo contido nestes sais é pouco disponível para aves e suínos, pois esses animais carecem da enzima fitase para romper e separar o fósforo da molécula de inositol, o que faz com que grande parte do fósforo fítico seja excretada pelas fezes.

Numerosos estudos têm sido conduzidos visando otimizar o aproveitamento do fósforo dos alimentos e reduzir sua excreção, ajustando o consumo desse mineral às reais necessidades dos animais. Assim, são realizados estudos em diversas espécies em várias fases para avaliação das exigências, da digestibilidade e da disponibilidade deste nutriente e da incorporação de aditivos na dieta, como a fitase exógena (Jongbloed \& Kemme, 1990; O’Quinn et al., 1997; Shen et al., 2002).

A disponibilidade e digestibilidade são formas de se avaliar a utilização biológica deste mineral pelos animais. Jongbloed \& Kemme (1990) sugerem que a disponibilidade de fósforo pode ser estimada pelos coeficientes de digestibilidade aparente desse elemento contido nos alimentos, o que, de acordo com O'Quinn et al. (1997), tem vantagens econômicas e práticas por ser um ensaio relativamente simples e rápido, que evita o abate dos animais.

Este trabalho foi conduzido com o objetivo de determinar os valores de coeficientes de digestibilidade aparente (CDAP) e verdadeira (CDVP) do fósforo de alimentos de origem vegetal utilizados em rações para suínos em crescimento e em terminação.

\section{Material e Métodos}

O experimento foi conduzido nas instalações do Setor de Suinocultura do Departamento de Zootecnia da Universidade Federal de Viçosa. O delineamento experimental utilizado foi o inteiramente casualizado, em arranjo fatorial $2 \times 2 \times 13$ (metodologias $\times$ fases $\times$ dietas-alimentos), com três repetições por tratamento e um animal por unidade experimental.

As metodologias utilizadas, simultaneamente, foram as da coleta total de fezes e a do indicador fecal óxido crômico $\left(\mathrm{Cr}_{2} \mathrm{O}_{3}\right)$. Utilizaram-se 36 animais, machos castrados, com peso inicial de $25,0 \pm 3,0 \mathrm{~kg}$ na fase de crescimento e 36 animais com peso de 60,0 $\pm 5,0 \mathrm{~kg}$ na fase de terminação. Os animais foram alojados, individualmente, em gaiolas de metabolismo semelhantes às descritas por Pekas (1968), localizadas em prédio de alvenaria com piso de concreto, ripado nas laterais e coberto com telhas francesas, onde foram mantidos durante 12 dias (sete para adaptação às gaiolas e às rações experimentais e cinco para coleta de fezes).

Os tratamentos consistiram de 11 alimentos de origem vegetal, uma ração-referência suplementada com aminoácidos sintéticos e contendo $0,17 \%$ de P total, de modo a atender as exigências dos animais segundo Rostagno et al. (2000), exceto para o fósforo, e uma dieta com baixo conteúdo de fósforo (0,03\%), utilizada para estimar as perdas de fósforo endógeno excretado nas fezes (Tabela 1).

Tabela 1 - Composição da ração-referência e de baixo fósforo

\begin{tabular}{lcc} 
Ingrediente & $\begin{array}{c}\text { Ração-referência } \\
(\%)\end{array}$ & $\begin{array}{c}\text { Ração baixo teor } \\
\text { de fósforo (\%) }\end{array}$ \\
\hline Milho & 40,59 & - \\
Farinha de milho & 20,00 & 29,90 \\
Açúcar & 10,00 & 25,00 \\
Amido & 10,00 & 25,00 \\
Farelo de soja & 8,00 & - \\
Óleo de soja & 2,80 & 4,00 \\
Plasma sangüíneo & 2,73 & 7,51 \\
Calcário & 2,16 & 2,50 \\
Concentrado protéico de soja & 1,50 & - \\
Sal comum & 0,21 & 0,09 \\
Mistura mineral ${ }^{1}$ & 0,13 & 0,13 \\
Mistura vitamínica & & 0,07 \\
BHT & 0,06 & 0,01 \\
Inerte & 0,01 & 4,504 \\
L-lisina & $1,00^{3}$ & 0,50 \\
DL-metionina & 0,44 & 0,48 \\
L-treonina & 0,16 & 0,24 \\
L-triptofano & 0,15 & 0,07 \\
Total & 0,06 & 100,00
\end{tabular}

Composição calculada

\begin{tabular}{lcc}
\hline Proteína bruta (\%) & $12,20(12,54)^{5}$ & $8,79(7,96)^{5}$ \\
Energia digestível, kcal/kg & 3.602 & 3.660 \\
Fibra bruta (\%) & 1,62 & 1,78 \\
Ca (\%) & $0,88(0,88)^{5}$ & $0,98(0,98)^{5}$ \\
P total (\%) & $0,17(0,21)^{5}$ & $0,03(0,02)^{5}$
\end{tabular}

${ }^{1}$ Composição por quilo do produto: $\mathrm{Fe}-180 \mathrm{~g} ; \mathrm{Cu}-20 \mathrm{~g} ; \mathrm{Co}-4 \mathrm{~g} ; \mathrm{Mn}-$ 80 g; Zn - 140 g; I - 4 g; veículo q.s.p. - 1.000 g. ${ }^{2}$ Composição por quilo do produto: vit. A - 9.000.000 Ul; vit. D3 - 1.500.000 Ul; vit. E - 10.000 Ul; vit. B1 - 2 g; vit. B2 - 5 g; vit. B6 - 30 g; ácido pantotênico - 25 g; vit. K3 - 4 g; vit. B12 - 40 mg; ácido nicotínico - 40 g; antioxidante - 30 g; selênio $23 \mathrm{mg}$; veículo q.s.p. - $1.000 \mathrm{~g} \cdot{ }^{3}$ Areia lavada; ${ }^{4}$ Sabugo de milho moído ${ }^{5}$ Valores determinados no Laboratório de Nutrição Animal do Departamento de Zootecnia - UFV. 
Os alimentos avaliados substituíram a ração-referência em quantidades variáveis, de modo que cada um forneceu $0,15 \%$ de fósforo total, conforme descrito a seguir: milho 62,50\%; sorgo - 55,56\%; farelo de glúten de milho 22\% PB - 21,13\%; farelo de glúten de milho 60\% PB - 61,91\%; farelo de algodão 30\% PB - 14,29; farelo de algodão 40\% PB $14,71 \%$; farelo de trigo - 15,96; farelo de soja - 25,42; concentrado protéico de soja - 22,73\%; soja integral extrusada - 30,61\%; e levedura desidratada de cana-deaçúcar - 16,48\%. A cada dieta experimental foram adicionados $0,5 \%$ de óxido crômico $\left(\mathrm{Cr}_{2} \mathrm{O}_{3}\right)$ como indicador fecal em substituição ao inerte.

As dietas experimentais foram fornecidas de acordo com o peso metabólico $\left(\mathrm{kg}^{0,75}\right)$ de cada animal, em duas refeições diárias, às 8 e 17 h, e a água foi fornecida à vontade.

A coleta de fezes e a preparação das amostras para análises foram realizadas conforme descrito por Gomes et al. (1989). As análises dos teores de matéria seca, fósforo total e óxido crômico foram realizadas no Laboratório de Nutrição Animal do Departamento de Zootecnia - UFV, de acordo com metodologias descritas por Silva (1990).

Foram determinados os consumos de matéria seca (g/dia) e de fósforo total (g/dia), o consumo de fósforo da ração-referência e dos alimentos (g/dia), o fósforo fornecido pelo alimento e pela ração-referência (\%), o fósforo na ração e nas fezes (\%), a excreção de fósforo (g/dia), o fator de indigestibilidade $\left(\mathrm{Cr}_{2} \mathrm{O}_{3}\right)$, o fator de indigestibilidade endógena e o fósforo excretado pelos animais que receberam a dieta com baixo teor de fósforo (fósforo endógeno, g/dia). Os dados obtidos foram utilizados nas fórmulas descritas por Jongbloed \& Kemme (1990) e Rostagno \& Featherston (1977) para determinação dos CDAP e CDVP do fósforo e os valores foram expressos com base na matéria seca.

Metodologia da coleta total:

Coeficiente de digestibilidade aparente do fósforo (CDAP) - (Jongbloed \& Kemme, 1990)

$\operatorname{CDAP}(\%)=\frac{\text { P ingerido }(\mathrm{g})-\mathrm{P} \text { excretado fezes }(\mathrm{g})}{\mathrm{P} \text { ingerido }(\mathrm{g})} \times 100$

Coeficiente de digestibilidade verdadeira do fósforo (CDVP)

$$
\operatorname{CDVP}(\%)=\frac{\begin{array}{c}
{[\text { P ingerido }(\mathrm{g})-(\mathrm{P} \text { excr. Fezes }(\mathrm{g})} \\
-\mathrm{P} \text { endógeno })]
\end{array}}{\text { P ingerido }(\mathrm{g})}
$$

Metodologia do indicador fecal $\left(\mathrm{Cr}_{2} \mathrm{O}_{3}\right)$ :

Fator de indigestibilidade (FI)

$$
\mathrm{FI}=\frac{\% \mathrm{Cr}_{2} \mathrm{O}_{3} \text { dieta }}{\% \mathrm{Cr}_{2} \mathrm{O}_{3} \text { fezes }}
$$

Coeficiente de digestibilidade aparente do fósforo (CDAP) (adaptado de Rostagno \& Featherston, 1977)

$$
\operatorname{CDAP}(\%)=\frac{\% \text { P dieta }-(\% \text { P fezes } \times \text { FI })}{\% \text { P dieta }} \times 100
$$

Coeficiente de digestibilidade verdadeira do fósforo (CDVP) (adaptado de Rostagno \& Featherston, 1977)

$$
\operatorname{CDVP}(\%)=\frac{\% \mathrm{P} \text { dieta }-(\% \mathrm{P} \text { fezes } \times \mathrm{FI}-\% \mathrm{Pe} \times \mathrm{FIe})}{\% \text { P dieta }} \times 100
$$

em que: Fie = fator de indigestibilidade da dieta baixo fósforo; $\mathrm{Pe}$ = fósforo endógeno excretado.

Os dados obtidos foram submetidos à análise de variância seguida de teste de comparação múltipla NeumanKeul's com 5\% de probabilidade, utilizando-se o pacote estatístico SAEG (2001).

\section{Resultados e Discussão}

As metodologias de coleta total de fezes e indicador fecal possibilitaram resultados semelhantes $(\mathrm{P}>0,05)$ na obtenção dos CDAP dos alimentos (Tabela 2) quando avaliadas as médias dos coeficientes obtidos nos diferentes alimentos, indicando que ambas as metodologias podem ser utilizadas na obtenção dos coeficientes de digestibilidade do fósforo.

Apesar disso, os coeficientes de digestibilidade de alguns alimentos, como o sorgo, apresentaram maior discrepância entre as duas metodologias. A metodologia do indicador fecal parece ter subestimado o coeficiente de digestibilidade do fósforo neste alimento, possivelmente em virtude das dificuldades atribuídas à metodologia utilizando óxido crômico. Halloran (1972) verificou maior variação entre os resultados obtidos no uso do óxido crômico e maiores fontes de variação nesta metodologia. Esse autor ressaltou a dificuldade de se distribuir uniformemente o óxido de cromo nas dietas experimentais, a correta amostragem e, ainda, as variações inerentes às análises laboratoriais. 
Tabela 2 - Coeficientes de digestibilidade aparente do fósforo dos alimentos (\%) em suínos em crescimento e em terminação

\begin{tabular}{|c|c|c|c|c|c|c|}
\hline Alimento & \multicolumn{3}{|c|}{ Fase de crescimento } & \multicolumn{3}{|c|}{ Fase de terminação } \\
\hline Milho $(0,31)^{2}$ & 39,77 & 33,01 & $36,39 \pm 4,64 a$ & 58,85 & 48,38 & $53,62 \pm 3,62 a$ \\
\hline Farelo glúten milho $22(0,69)$ & 25,62 & 25,18 & $25,40 \pm 1,49 b$ & 40,17 & 36,37 & $38,27 \pm 4,82 \mathrm{a}$ \\
\hline Farelo glúten milho $60(0,47)$ & 37,67 & 35,49 & $36,58 \pm 2,45 a$ & 44,68 & 35,26 & $39,97 \pm 5,60 \mathrm{a}$ \\
\hline Farelo de algodão $30(0,83)$ & 22,29 & 35,02 & $28,65 \pm 3,25 a$ & 36,02 & 36,35 & $36,18 \pm 3,92 \mathrm{a}$ \\
\hline Farelo de soja $(0,59)$ & 44,71 & 35,33 & $40,02 \pm 2,85 a$ & 48,46 & 26,49 & $37,47 \pm 6,94 a$ \\
\hline Concentrado protéico de soja $(0,88)$ & 37,82 & 23,34 & $30,58 \pm 5,67 a$ & 40,86 & 32,42 & $36,64 \pm 2,33 a$ \\
\hline Soja integral extrusada $(0,49)$ & 35,12 & 31,64 & $33,08 \pm 0,99 b$ & 53,89 & 46,64 & $50,26 \pm 5,69 a$ \\
\hline Levedura $(0,66)$ & 61,22 & 46,67 & $53,94 \pm 4,05 a$ & 55,42 & 64,07 & $59,74 \pm 3,99 a$ \\
\hline
\end{tabular}

Coeficiente de variação $=23,69 \%$.

Médias com letras diferentes, minúsculas na mesma linha, diferem $(P<0,05)$ entre si pelo teste Newman-Keul's

${ }^{1}$ Médias \pm erro-padrão.

2 Conteúdo de fósforo analisado, \%.

${ }^{3}$ Comparação de médias entre as metodologias dentro da fase.

A idade dos animais influenciou os valores de CDAP do fósforo dos alimentos sorgo, farelo de glúten de milho 22 e soja integral extrusada, que foram mais altos na fase de terminação $(P<0,05)$. Apesar disso, maiores valores numéricos de CDAP foram obtidos para todos os alimentos $(\mathrm{P}>0,05)$ na fase de terminação, exceto para o farelo de algodão 40 e farelo de soja, cujos valores de CDAP foram numericamente inferiores na fase final em relação aos obtidos na fase de crescimento, o que pode ser atribuído à metodologia do indicador fecal, que parece ter subestimado os valores encontrados na fase de terminação. Assim, animais na fase de terminação parecem aproveitar melhor o fósforo dos alimentos de origem vegetal. As possíveis diferenças no aproveitamento do fósforo com o aumento da idade do animal podem estar relacionadas ao tempo de retenção da digesta e aos valores de $\mathrm{pH}$ no trato digestivo, que são mais favoráveis à atividade fitásica (intrínseca do alimento) e à ação do ácido clorídrico em animais adultos em comparação a animais jovens (McElroy et al., 1991).

Os valores de CDAP obtidos para o milho nas fases de crescimento e terminação (36,39 e 53,62\%, respectivamente) foram superiores aos descritos por Jongbloed \& Kemme (1997) e Sauvant et al. (2003), que encontraram coeficientes de digestibilidade de 19,00 e 28,00\% como valores médios entre as fases de crescimento e terminação, utilizando a metodologia da coleta total. Valores semelhantes aos encontrados neste trabalho foram obtidos, na mesma fase, por Skiba et al. (2004), que determinaram valores de CDAP de $27,40 \%$ para animais nas fases de crescimento.

O valor de CDAP obtido na fase de crescimento foi de $23,22 \%$ e o encontrado na fase de terminação, de 39,38\% $(P<0,05)$. Esses valores foram semelhantes aos encontrados por Sauvant et al. (2003), de 30,00\%, como valor médio nas fases de crescimento e terminação.

Os valores de CDAP encontrados para o farelo de glúten de milho 22 (25,40 e 38,27\% para crescimento e terminação, respectivamente) diferiram significativamente entre as fases avaliadas $(\mathrm{P}<0,05)$, observando-se o maior valor na fase de terminação. Esses resultados foram superiores aos encontrados por Sauvant et al. (2003), de 22,00\% de CDAP como valor médio entre as duas fases. Para o farelo de glúten de milho 60 , não foi verificada influência da fase sobre os resultados (36,58 vs 39,97\% para as fases de crescimento e terminação, respectivamente) e o valor médio obtido $(38,28 \%)$ foi superior ao citado por esses autores $(19,00 \%)$.

Os alimentos farelo de soja, concentrado protéico de soja e os farelos de algodão apresentaram menores variações nos valores dos CDAP do fósforo quando comparadas as fases $(\mathrm{P}>0,05)$. A soja integral extrusada, no entanto, diferiu entre as fases de crescimento e terminação e apresentou maior CDAP do fósforo na fase final $(\mathrm{P}<0,05)$.

Os valores de CDAP do farelo de soja foram semelhantes entre as fases de crescimento e terminação (40,02 e 37,47\%, respectivamente) e similares aos descritos por Jongbloed \& Kemme (1997), que encontraram valores de 38,00\%. Werenko et al. (1997) também obtiveram na fase de crescimento valor similar de CDAP, 34,00\%. Valores um pouco inferiores (31,50\%), no entanto, foram encontrados por Gomes et al. (1989).

Existe grande variação nos coeficientes de digestibilidade aparente do fósforo do farelo de soja descritos na literatura, de 24,00 a 41,00\%, segundo Jongbloed \& Kemme (1997), e vários fatores podem contribuir para esta variação, como aqueles inerentes às amostras, a atividade fitásica intrín- 
seca das diferentes amostras de farelo de soja utilizadas nas pesquisas e o próprio conteúdo de fósforo da dieta (Fan et al. 2001), entre outros.

A soja integral extrusada, apesar de possuir conteúdo do fósforo total semelhante ao farelo de soja (0,49\% vs $0,59 \%$, respectivamente) apresentou maiores valores de CDAP na fase de terminação. Houve maior aproveitamento do fósforo deste alimento nesta fase, diferente do encontrado para o farelo de soja, no qual não houve influência da fase no aproveitamento deste nutriente. O melhor aproveitamento do fósforo do farelo de soja pode ser atribuído ao maior tempo de retenção da digesta e ao pH mais elevado, que podem ter contribuído para aumentar a digestibilidade do fósforo em animais adultos. Os valores de CDAP obtidos para a soja integral extrusada foram de 33,08\% para a fase de crescimento e $50,26 \%$ para a fase de terminação. Sauvant et al. (2003) encontraram para a soja integral extrusada CDAP de 32,00\% como valor médio entre suínos em crescimento e terminação.

O concentrado protéico de soja apresentou valores de CDAP de 30,58 e 36,64\% nas fases de crescimento e terminação, respectivamente. O concentrado protéico de soja é um alimento especial, derivado do processamento da soja e normalmente utilizado em dietas especiais para animais jovens. Assim, valores de coeficientes de digestibilidade do fósforo para comparações são escassos.

O coeficiente de digestibilidade aparente do farelo de trigo foi um dos mais elevados em ambas as fases analisadas: 47,96 e 53,56\% nas fases de crescimento e terminação, respectivamente. Esses dados são semelhantes aos encontrados por Gomes et al. (1989), de 45,39\%, e superiores aos obtidos por Jongbloed \& Kemme (1997) e CVB (1998), de 38,00 e $20,00 \%$, respectivamente. Alguns pesquisadores destacam a presença de atividade fitásica intrínseca no grão de trigo, o que melhoraria o aproveitamento do fósforo presente no complexo fitato dos subprodutos do trigo (Rebollar \& Mateos, 1999; Skiba et al, 2004).

A levedura desidratada de cana-de-açúcar apresentou CDAP de 53,94 e 59,74\% para as fases de crescimento e terminação, respectivamente $(\mathrm{P}>0,05)$. Apesar de não haverem dados comparáveis na literatura quanto à digestibilidade do fósforo deste alimento, Sauvant et al. (2003) afirmam que o conteúdo de fósforo fítico presente na levedura corresponde a apenas $10 \%$ do conteúdo de fósforo total, portanto, grande parte do fósforo deste alimento pode ser utilizado pelos animais.

De forma semelhante aos valores de coeficientes de digestibilidade aparente do fósforo, não houve influência $(\mathrm{P}>0,05)$ das metodologias utilizadas, fato confirmado pelos valores médios obtidos em cada metodologia (Tabela 3). As diferenças entre os valores de CDVP do concentrado protéico de soja e da levedura parecem ter sido subestimadas na metodologia do indicador fecal.

Não houve interação entre as metodologias e os alimentos ou entre as fases. Interação significativa foi encontrada somente entre as fases e alguns alimentos, como milho, sorgo, farelo de glúten de milho 22 e soja integral extrusada, cujos maiores valores foram obtidos na fase de terminação $(\mathrm{P}<0,05)$, confirmando a influência da fase sobre ao aproveitamento do fósforo destes alimentos.

Para os demais alimentos avaliados, os valores numéricos de CDVP obtidos na fase de terminação foram mais altos que na fase de crescimento, com exceção do farelo de algodão 40, embora a diferença entre os valores tenha sido mínima. Os altos valores de coeficientes de variação associados provavelmente não permitiram a detecção de diferenças estatísticas.

O fósforo presente nas fezes é composto de fósforo de origem dietética e perdas endógenas. Os alimentos com menor conteúdo de fósforo total, como milho, sorgo, farelo de glúten de milho 22, farelo de glúten de milho 60 e soja integral extrusada apresentaram as maiores diferenças entre os coeficientes de digestibilidade aparente e verdadeira, pois o fósforo de origem endógena participa em grande proporção do conteúdo de fósforo total que é excretado nas fezes, o que resulta, conseqüentemente, em maiores diferenças entre coeficientes de digestibilidade aparente e verdadeira.

Segundo Shen et al. (2002), devem ser consideradas as perdas endógenas de fósforo que ocorrem por meio do muco, de células de descamação e de enzimas para determinação dos coeficientes de digestibilidade do fósforo, pois estes componentes representam uma via importante de excreção deste mineral e essas perdas são mais expressivas em ingredientes com baixo teor de fósforo. Esses autores sugeriram ainda que os valores de fósforo digestível aparente do milho, por exemplo, subestimam em aproximadamente $35 \%$ a verdadeira utilização do fósforo.

Os valores de CDVP do milho foram $54,78 \%$ na fase de crescimento e $81,86 \%$ na fase de terminação. Na fase de crescimento, os valores foram similares aos citados por Shen et al. (2002), de 59,80\% de digestibilidade do fósforo para animais em crescimento utilizando a metodologia da relação dos coeficientes de regressão (slope ratio).

Os valores de CDVP obtidos para o sorgo foram de $51,45 \%$ na fase de crescimento e $82,48 \%$ na fase de terminação, resultados semelhantes aos encontrados para o aproveitamento do fósforo do milho. 
Tabela 3 - Coeficientes de digestibilidade verdadeira do fósforo de alimentos (\%) em suínos em crescimento e em terminação

\begin{tabular}{|c|c|c|c|c|c|c|}
\hline \multirow[t]{2}{*}{ Alimento } & \multicolumn{3}{|c|}{ Crescimento } & \multicolumn{3}{|c|}{ Terminação } \\
\hline & Coleta total & Indicador fecal & Média \pm EPM $^{1}$ & Coleta total & Indicador fecal & Média $\pm \mathrm{EPM}^{1}$ \\
\hline Milho $(0,31)^{2}$ & 57,31 & 52,25 & $54,78 \pm 4,53 b$ & 80,89 & 82,83 & $81,86 \pm 2,79 a$ \\
\hline Farelo glúten milho $22(0,69)$ & 33,11 & 33,39 & $33,25 \pm 1,49 b$ & 49,58 & 49,17 & $49,37 \pm 4,74 a$ \\
\hline Farelo glúten milho $60(0,47)$ & 49,13 & 48,08 & $48,61 \pm 4,20 \mathrm{a}$ & 59,10 & 56,47 & $57,78 \pm 5,22 \mathrm{a}$ \\
\hline Farelo algodão $30(0,83)$ & 28,18 & 41,49 & $34,83 \pm 3,37 a$ & 43,42 & 49,36 & $46,39 \pm 4,22 \mathrm{a}$ \\
\hline Farelo de soja $(0,59)$ & 55,18 & 46,82 & $51,00 \pm 2,68 a$ & 61,61 & 45,16 & $53,38 \pm 6,13 a$ \\
\hline Concentrado protéico de soja $(0,88)$ & 43,77 & 29,87 & $36,82 \pm 5,60 \mathrm{a}$ & 48,35 & 42,83 & $45,59 \pm 1,84 a$ \\
\hline Soja integral extrusada $(0,49)$ & 45,90 & 43,47 & $44,68 \pm 0,82 b$ & 67,43 & 66,43 & $66,93 \pm 5,47 a$ \\
\hline Levedura $(0,66)$ & 69,07 & 55,30 & $62,19 \pm 3,92 \mathrm{a}$ & 65,30 & 76,54 & $70,92 \pm 4,31 \mathrm{a}$ \\
\hline
\end{tabular}

Média Método $\pm \mathrm{EP}^{3} \quad 49,15 \pm 2,31 \mathrm{a} \quad 44,70 \pm 1,71 \mathrm{a}$

Coeficiente de variação $=17,66 \%$.

Médias com letras diferentes, minúsculas na mesma linha, diferem $(P<0,05)$ entre si pelo teste Newman-Keul's.

${ }^{1}$ Médias \pm erro-padrão.

2 Conteúdo de fósforo analisado, \%.

3 Comparação de médias entre as metodologias dentro da fase.

No farelo de glúten de milho 22\% de PB, os CDVP foram de 33,25 e 49,37\% nas fases de crescimento e terminação, respectivamente. Houve influência da fase sobre o aproveitamento do fósforo deste alimento $(\mathrm{P}<0,05)$ pelos animais em terminação.

Os coeficientes de CDVP do fósforo do farelo de glúten de milho $60 \%$ de PB foram de 48,61 e 57,78\% nas fases de crescimento e terminação, portanto, não houve diferença entre as fases. O valor médio de CDVP para o farelo de glúten de milho 60 (53,20\%) foi similar ao descrito pelo NRC (1998), que cita valores de 53,10\% para a disponibilidade do fósforo. Apesar das diferentes metodologias, a semelhança nos valores pode indicar aproveitamento similar do fósforo no farelo de glúten 60 .

As variações nos valores dos CDVP dos alimentos farelo de soja, concentrado protéico de soja, soja integral extrusada e os farelos de algodão foram maiores que as do CDAP quando consideradas as perdas endógenas. $\mathrm{O}$ aumento nos valores foi próximo a 30\% e a maior diferença foi observada para o farelo soja e para a soja integral extrusada. Essa diferença pode ser atribuída ao menor conteúdo de fósforo, principalmente no farelo de soja e na soja integral extrusada.

Os valores de CDVP obtidos para o farelo de soja nas fases de crescimento e terminação (51,00 e 53,38\%, respectivamente) foram semelhantes aos reportados por Gomes et al. (1989), que, também utilizando as metodologias de coleta total e indicador fecal, encontraram valor médio de $46,44 \%$, principalmente quando considerado o coeficiente de variação a que estes valores estão associados. Ajakaiye et al. (2003) também obtiveram valor semelhante, 51,00\% para o CDVP, ao utilizarem a metodologia da coleta da digesta ileal. Esses autores citaram ainda que no intestino grosso não ocorre absorção deste mineral e pode ser utilizada a técnica da coleta de digesta ileal para determinação da digestibilidade do fósforo dos alimentos.

Dos alimentos analisados, o farelo de trigo apresentou a menor variação entre os CDAP e CDVP, cujos valores de CDVP foram de 52,19 e 59,28\% (crescimento e terminação, respectivamente). Esses resultados corroboram os encontrados por Gomes et al. (1989), que obtiveram valor de CDVP igual a 52,59\% para o farelo de trigo como valor médio para animais em crescimento e terminação.

A levedura desidratada também apresentou pequena variação entre os valores médios de CDAP e CDVP, além de baixo conteúdo de fósforo fítico (Sauvant et al., 2003), o que pode explicar os altos coeficientes de digestibilidade do fósforo, 62,19 e 70,92\% nas fases de crescimento e terminação, respectivamente.

Tabela 4 - Conteúdo de fósforo total (P total) e fósforo digestível verdadeiro dos alimentos de origem vegetal nas fases de crescimento (PDVC) e terminação (PDVT) (\%)

\begin{tabular}{lccc}
\hline & P total & PDVC & PDVT \\
\hline Milho & 0,31 & 0,17 & 0,25 \\
Sorgo & 0,23 & 0,12 & 0,19 \\
Farelo glúten milho 22 & 0,69 & 0,23 & 0,34 \\
Farelo glúten milho 60 & 0,47 & 0,23 & 0,27 \\
Farelo de algodão 30 & 0,83 & 0,29 & 0,39 \\
Farelo de algodão 40 & 1,02 & 0,47 & 0,42 \\
Farelo de trigo & 1,25 & 0,65 & 0,74 \\
Farelo de soja & 0,59 & 0,30 & 0,31 \\
Concentrado protéico de soja & 0,88 & 0,32 & 0,40 \\
Soja integral extrusada & 0,49 & 0,22 & 0,33 \\
Levedura de cana & 0,66 & 0,41 & 0,47 \\
\hline
\end{tabular}

Valores expressos na matéria natural.

${ }^{1}$ Valores analizados no Laboratório de Nutrição Animal - DZO/UFV. 


\section{Conclusões}

Não foram encontradas diferenças entre as metodologias de coleta total de fezes e do indicador fecal na obtenção dos valores de coeficientes de digestibilidade aparente e verdadeira dos alimentos avaliados. Os maiores valores foram obtidos em suínos na fase de terminação. Os coeficientes de digestibilidade verdadeira do fósforo determinados em suínos em crescimento e terminação foram, respectivamente, 54,78 e $81,86 \%$ para o milho; 51,45 e 82,48\% para o sorgo; 33,25 e 49,37\% para o farelo de glúten de milho 22\% de PB; 48,61 e 57,78\% farelo de glúten de milho $60 \%$ de PB; 34,83 e 46,39\% para o farelo de algodão com 30\% de PB; 46,38 e 41,51\% para o farelo de algodão com $40 \%$ de PB; 52,19 e 59,28\% para o farelo de trigo; 51,00 e $53,38 \%$ para o farelo de soja; 36,68 e $45,59 \%$ para o concentrado protéico de soja; 44,68 e 66,93\% a soja integral extrusada e, 62,19 e 70,92\% para a levedura desidratada de cana de açúcar.

\section{Literatura Citada}

AJAKAIYE, A.; FAN, M.Z.; ARCHBOLD,T. et al. Determination of true digestive utilization of phosphorus and the endogenous phosphorus outputs associated with soybean meal for growing pigs. Journal of Animal Science, v.81, p.2766-2775, 2003.

CENTRAL VEEVOEDERBUREAU - CVB. Veevoedertabel: Gegevens over chemische samenstelling, verteerbaarheid envoederwaarde van voedermiddelen. Lelystad: 1998. p.94.

FAN, M.Z.; ARCHBOLD, T.; SAUER, W.C. et al. Novel methodology allows simultaneous measurement of true phosphorus digestibility and the gastrointestinal endogenous phosphorus outputs in studies with pigs. Journal of Nutrition, v.131, p.2388-2396, 2001.

GOMES, P.C.; ROSTAGNO, H.S.; COSTA, P.M.A. et al. Digestibilidade aparente e verdadeira do fósforo de cinco alimentos, determinada em suínos de diferentes idades. Revista Brasileira de Zootecnia, v.18, n.1, p.77-90, 1989.

HALLORAN H.R. A major problem in metabolizable energy Determinations of feedstuffs for poultry. Feedstuffs, v.14, p.38-39, 1972.

JONGBLOED, A.W.; KEMME, P.A. Apparent digestible phosphorus in the feeding of pigs in relation to availability, requirement and environment. Digestible phosphorus in feedstuffs from plant and animal origin. Netherland Journal Agriculture Science, v.38, p.56-75, 1990.
JONGBLOED, A.W.; KEMME, P.A. Disponibilidad del fósforo em ingredientes alimentícios para ganado porcino. In: CURSO DE ESPECIAliZACIÓN FEDNA, 13., 1997, Madrid. Apostila... Madrid: 1997. p.191-201.

KEMME, P.A.; RADCLIFFE, J.S.; JONGBLOED, A.W. et al. Factors affecting phosphorus and calcium digestibility in diets for growing-finishing pigs Journal of Animal Science, v.75, p.2139-2146, 1997.

McELROY, S.T.; LINK, J.E.; DOWDY, R.P. et at. Influence of age and magnesium on calcium metabolism in rats. Journal of Nutrition, v.121, p.492-497, 1991.

NATIONAL RESEARCH COUNCIL - NRC. Nutrient requirements of swine. 10.ed. Washington, D.C.: National Academy Press, 1998. 189p.

O’QUINN, P.R.; KNABE, D.A.; GREGG, E.J. Digestible phosphorus needs of terminal-cross growing-finishing pigs. Journal of Animal Science, v.75, p.1308-1318, 1997.

PEKAS, J.C. Versatible swine labotarory apparatus for physiologic and metabolic studies. Journal of Animal Science, v.2, n.5, p.1303-1306, 1968.

REBOLLAR, P.G.; MATEOS, G.G. El fósforo en nutrición animal. Necesidades, valoración de materias primas y mejora de disponibilidad. In: CURSO DE ESPECIALIZACIÓN FEDNA, 15., 1999, Madrid. Apostila... Madrid: 1999. p.19-64.

ROSTAGNO, H.S.; FEATHERSTON, W.R. Estudos de métodos para determinação de disponibilidade de aminoácidos. Revista Brasileira de Zootecnia, v.6, n.1, p.64-75, 1977.

ROSTAGNO, H.S.; ALBINO, L.F.T.; DONZELE, J.L. et al. Tabelas brasileiras para aves e suínos: composição de alimentos e exigências nutricionais. Viçosa, MG: Universidade Federal de Viçosa, 2000. 141p.

SAUER, W.C.; OZIMEK, L. Digestibility of amino acids in swine : Results and their practical applications. A review. Livestock Production Science, v.15, p.367-388, 1986.

SAUVANT, D.; PEREZ, J.M.; TRAN, G. Tablas de composición y de valor nutritivo de las matérias primas destinadas a los animales de interés ganadero. Paris: Institute National de la Recherche Agronomique, 2003. p.212. (versão espanhola).

SHEN, Y.; FAN, M.Z.; AJAKAIYE, A. et al. Use of the regression analysis technique to determine the true phosphorus digestibility and the endogenous phosphorus output associated with corn in growing pigs. Journal of Nutrition, v.132, p.1199-1206. 2002.

SILVA, D.J. Análise de alimentos (métodos químicos e biológicos). Viçosa, MG: Universidade Federal de Viçosa, 1990. 165p

SKIBA, F.; CALLU, P.; CASTAING, J. et al. Variabilité intra-matière première de la digestibilité du phosphoredes céréales et du pois chez le porc en croissance. Journées Recherche Porcine, v.36, p.9-16, 2004.

UNIVERSIDADE FEDERAL DE VIÇOSA - UFV. SAEG - Sistema de análises estatísticas e genéticas. Versão 8.0. Viçosa, MG: 2001. 142p.

WERENKO, D.; FANDREJEWSKI, H.; ZEBROWSKA, T. et al. Bioavailability of phosphorus in feeds of plant origin for pigs. Asian Journal of Animal Science, v.10, p.551-566, 1997. 